\title{
Effects of Tested Rules on Work-Rest Time in Volleyball
}

\author{
Mladen Stanković ${ }^{1 *}$, Dušan Perić², Guillermo Ruiz-Llamas ${ }^{1}$, Miriam E. Quiroga-Escudero ${ }^{1}$ \\ ARTIGO ORIGINAL | ORIGINAL ARTICLE
}

\begin{abstract}
The aim of this study was to determine the influence of new rules tested at the inaugural Men's Under 23 (U23) World Championship (set to 21 points and 15 seconds between the end of a point and the new serve) on all aspects of time in volleyball matches. The study sample comprised 36 matches partially segmented into 123 sets and 4583 points played. Applying one-way ANOVA, it was shown that the active part of the set and the whole match last slightly more than one third of the total time. The most frequent rally duration was 5 to 10 seconds ( $43.5 \%$ of points). As sets became more unpredictable and approached the end, rest time between points was longer. Time analysis of volleyball matches is important as it helps with proper development of physical preparation for players, gives coaches insight into appropriate match flow and provides a clear time frame of each part of a volleyball match for organisers of competitive events, pools, championships and tournaments.

Keywords: elite male volleyball, match duration, set phases, rally duration, time
\end{abstract}

\section{INTRODUCTION}

The sport of volleyball has no time limits on the length of official matches. The first team to win 3 sets is the match winner (Fédération Internationale de Volleyball [FIVB], 2012). The duration of a volleyball match has changed over time. The length of a match obviously depends on its parts: scoring system, rally length (work time of the game), rest time (time between rallies, substitutions, sanctions, technical and team time-outs, time between sets, injuries, and other technical aspects) and level of the players (Häyrinen et al., 2011). The rally is the basic unit of one point, the time when a team can score a point. It is differentiated from the other parts of the game, which are considered rest time (Fellingham, Collings, \& McGown, 1994).

Changes to the scoring system in beach volleyball introduced by Fédération Internationale de Volleyball (FIVB) and Association of Volleyball Professionals (AVP) to satisfy TV broadcasting needs was a major factor in the growth of this sport (Giatsis, 2003). At the inaugural FIVB U23 Men's World Championship, held in Brazil in October 2013, new rules were tested with the idea of modernising volleyball and making it more appealing for fans both at matches and watching television (FIVB, 2013a). Obviously, the main way to change match duration is to modify the scoring system, and this has been done several times (Ureña, Gallardo, Delgado, Hernández, \& Calvo, 2000) during the history of volleyball. Studies of beach volleyball and volleyball found that match duration changed significantly after changes to the scoring system (Giatsis, 2003; Kountouris \& Laios, 2000).

The changes tested (set to 21 points, excluding the fifth set to 15 points, with two points minimum difference at the end of sets; server has 15 seconds after the finished point to perform serve - 10 seconds to prepare and 5 seconds to execute the serve) were the first officially tested modifications of the Rally Point System (FIVB, 2013a; FIVB, 2015).

The results can provide an understanding of the effect of the rule changes and help to identify the best way to prepare volleyball teams physically, mentally and tactically, not only at the highest level, but also in the various stages of youth development. At the same time, this study can help the FIVB to make volleyball more attractive for audiences and television companies,

\footnotetext{
Manuscript received at April 15 ${ }^{\text {th }} 2016$; Accepted at December $8^{\text {th }} 2016$

${ }^{1}$ Universidad de Las Palmas de Gran Canaria, Las Palmas de Gran Canaria, Spain

${ }^{2}$ Faculty of Sport and Tourism, Novi Sad, Serbia

*E-mail: mladen_stankovic@yahoo.com
} 
and contribute to the development of volleyball in general.

The purpose of this study was to determine the detailed effects of the tested rules (set to 21 points and 15 seconds maximum to next serve after finished point) on time in volleyball matches.

\section{METHOD}

\section{Participants}

The analysis comprised 36 hours from 36 matches of the 38 games played at the U23 Men's World Championships in Uberlandia (Brazil). For the first time, a world championship was organised for under 23 male players, and competition took place in October 2013, with 12 national teams (144 players) participating. The FIVB organised the tournament following the competition system, testing two new rules: set to 21 points (excluding the fifth set, to 15 points) with a two-point minimum difference at the end of sets, and 15 seconds for the server to execute the serve after the finished point (FIVB, 2013b).

FIVB officially authorised the use of all videos of matches and data from the Volleyball Information System (VIS) and the FIVB website. This study was performed in accordance with the Helsinki Declaration of 1975.

\section{Measures}

Competition structure

Competition had two rounds: group phase (Pool A and B), and semi-finals and finals. In the group phase 30 matches were played and in the semi-finals and finals 8 matches were played. The 12 teams, divided into 2 groups of 6 , played according to the round-robin system to determine the ranking and were classified from 1st to 6th. The team ranked $3^{\text {rd }}$ in Pool A played the team ranked $4^{\text {th }}$ in Pool B. The team ranked $3^{\text {rd }}$ in Pool B played the team ranked $4^{\text {th }}$ in Pool A. The losers of these semi-final matches played for $7^{\text {th }}$ and $8^{\text {th }}$ final places and the winners played for $5^{\text {th }}$ and $6^{\text {th }}$ places. The team ranked $1^{\text {st }}$ in Pool A played the team ranked $2^{\text {nd }}$ in Pool $B$. The team ranked $1^{\text {st }}$ in Pool B played the team ranked $2^{\text {nd }}$ in Pool A. The losers of the semi-final matches played for $3^{\text {rd }}$ and $4^{\text {th }}$ place and the winners played for $1^{\text {st }}$ and $2^{\text {nd }}$ place (FIVB, 2013c).

\section{Variables}

Palao, Valadés, and Ortega (2012) studied the variables of match duration, total rallies per set and match, number of sets, team that won the set and the match, and type of match, established through the point difference between teams and gender. Häyrinen et al. (2011) analysed the duration of rallies, sets (no 5th sets), and breaks between rallies (no time-outs or breaks between sets). Vilamitjana et al. (2008) studied the time variables of work time during the set: total set time minus rest time (time-outs, player substitution time and time for the ball to reach the serve). They also analysed total jumps and total work time per subject.

In this study, all parts of the match duration were used as variables:

1. Work time (time between the referee's whistle for serve and the end of the point).

2. Rest time:

A. Time after the whistle for finished point until the whistle for serve.

B. Team time-out:

a) Time before the whistle for the beginning of team time-out.

b) Time between two whistles (timeout).

c) Time after the whistle for the end of team time-out.

C. Technical time-out:

a) Time before the whistle for the beginning of technical time-out.

b) Time between whistles.

c) Time after the whistle for the end of technical time-out.

D. Player substitutions:

a) Time before the whistle for substitution.

b) Time between whistles.

c) Time after the whistle for the end of substitution.

E. Player sanctions:

a) Time before the whistle for sanction.

b) Time between whistles.

c) Time after the whistle for the end of sanction.

F. Time between sets (time after the whistle for the end of last point until whistle for new set). 
G. Player injury time.

H. Time of other technical aspects (fixing fallen antenna, problem with referee's chair):

a) Time before the whistle for fixing the technical problem.

b) Time between whistles.

c) Time after the whistle for the end of the technical problem.

FIVB technicians specially trained to use the VIS, who were approved, supervised and appointed by the FIVB Technical Commission, collected the data. VIS software processes all data collected and is one of the two methods most commonly used by coaches and observers to assess individual and collective performance of volleyball players in each phase of the match. The variables were assessed by methodical observation of every second of the games. To ensure reliability of the observation, a single observer with experience in volleyball scouting and good knowledge of volleyball observed all matches. The intraobserver Cohen's Kappa values obtained in observation of all the variables were higher than 0.81 , the minimum value to be considered almost perfect agreement (Landis \& Koch, 1977). To ensure the time reliability of the measurement, the same procedure was performed twice, in an interval of 10 days, and Cohen's Kappa values higher than 0.81 were obtained.

\section{Procedures}

Part of the data was collected by watching all matches and the remaining data were taken from the VIS, on the FIVB website. All data were recorded on an analysis scheme form, used to define and examine the variables (Tsimpiris, Tsamourtzis, Sfingos, Zaggelidis, \& Zaggelidis, 2006). The FIVB authorised official collection of match videos and data from the VIS and the FIVB website. All matches were filmed using a PANASONIC HC-V720HD digital camcorder in AVCHD format. The camera was always located behind the court at a height of $5 \mathrm{~m}$ above the floor (Claver, Jiménez, Gil, Moreno, \& Moreno, 2013) to give the best angle to follow everything happening on and beside the court.
VIS software has been used in various studies (Marcelino \& Mesquita, 2008; Marcelino, Mesquita, \& Afonso, 2008; Marcelino, Mesquita, Palao, \& Sampaio, 2009). Its purpose is to quantify individual skills and it is accepted as a valid instrument in volleyball research.

\section{Statistical analysis}

IBM SPSS Statistics V19 software was used for the statistical analysis. All data were primarily processed by descriptive statistic procedures for each variable. One-way ANOVA was applied to test the significance of differences between the arithmetical means at different phases of the set and in sets with different levels of win. For more in-depth analysis and because of a small number of unbalanced observations in different categories of "time between sets", the Kruskal-Wallis nonparametric test was used. All tests were performed at the level of significance of 0.05 ( $\mathrm{p}<$ 0.05).

\section{RESULTS}

After measuring each part of total match duration, it was determined that total work time (time when the ball is in play) is a significantly smaller part than rest time, which has many components. Work time of the match and the set last slightly more than one third of the total time (Figures 1 and 2).

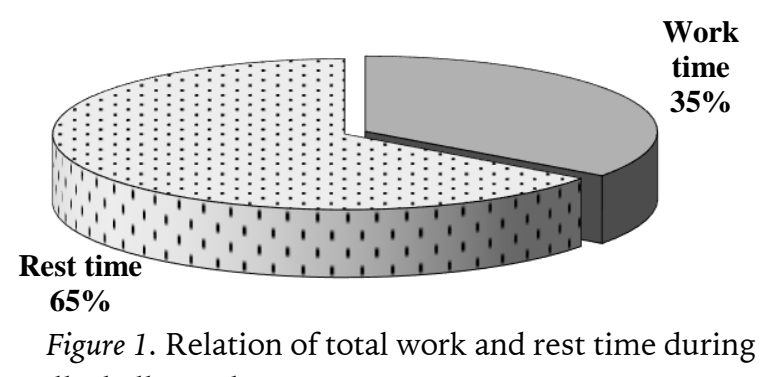
a volleyball match.

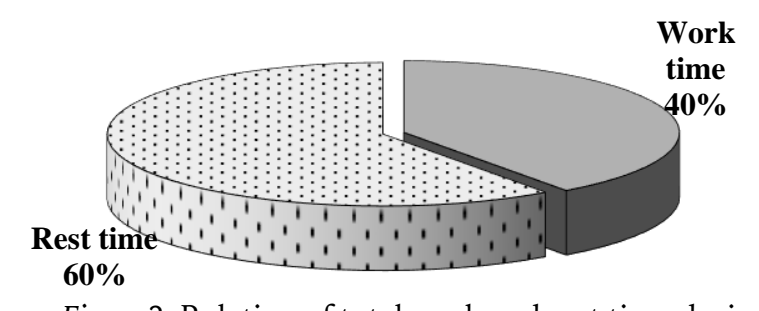

Figure 2. Relation of total work and rest time during an average set. 
The longest element of rest time during a volleyball match corresponds to periods between rallies ( $27.37 \%$ of total match duration) and both time-outs (19.12\%), followed by pauses between sets $(12.04 \%)$ and substitutions $(6.05 \%)$ (Table $1)$.

Table 1

Mean duration of each part of the match

\begin{tabular}{|c|c|c|c|c|c|c|c|c|}
\hline Variable & $N$ & $\begin{array}{l}\text { Mean } \\
(s)\end{array}$ & $\begin{array}{l}\text { Std. Dev. } \\
\text { (s) }\end{array}$ & $\begin{array}{l}\text { Std. Error } \\
\text { (s) }\end{array}$ & $\begin{array}{l}\text { Min. } \\
(s)\end{array}$ & $\begin{array}{c}\text { Max. } \\
\text { (s) }\end{array}$ & $\begin{array}{l}\text { Share of } \\
\text { Set }(\%)\end{array}$ & $\begin{array}{c}\text { Share of } \\
\text { Match (\%) }\end{array}$ \\
\hline Point duration & 4588 & 11.50 & 4.38 & .065 & 2.84 & 41.50 & 39.78 & 34.99 \\
\hline Time after point & 3568 & 11.57 & 2.08 & .035 & 3.17 & 47.17 & 31.12 & 27.37 \\
\hline Time-out & & & & & & & 14.82 & 13.03 \\
\hline Before the whistle & 313 & 8.04 & 3.77 & .213 & .17 & 35.50 & 1.90 & 1.67 \\
\hline Between whistles & 326 & 35.68 & 5.45 & .302 & 24.33 & 64.33 & 8.77 & 7.71 \\
\hline Time after the whistle & 325 & 16.92 & 5.46 & .303 & 1.84 & 53.00 & 4.15 & 3.65 \\
\hline Technical time-out & & & & & & & 6.92 & 6.09 \\
\hline Before the whistle & 119 & 3.75 & 2.08 & .190 & .84 & 13.50 & .34 & .30 \\
\hline Between whistles & 119 & 59.73 & 4.02 & .368 & 53.33 & 76.17 & 5.36 & 4.71 \\
\hline Time after the whistle & 119 & 13.63 & 4.89 & .449 & .00 & 26.17 & 1.22 & 1.08 \\
\hline Substitution & & & & & & & 6.88 & 6.05 \\
\hline Before the whistle & 413 & 6.61 & 3.09 & .152 & 1.00 & 24.17 & 2.06 & 1.81 \\
\hline Between whistles & 473 & 10.27 & 4.72 & .217 & 2.67 & 60.17 & 3.66 & 3.22 \\
\hline Time after the whistle & 409 & 3.77 & 3.01 & .149 & .84 & 21.00 & 1.16 & 1.02 \\
\hline Time between sets & 87 & 208.81 & 27.66 & 2.966 & 143.84 & 399.33 & / & 12.04 \\
\hline Sanction & & & & & & & .31 & .27 \\
\hline Before the whistle & 10 & 14.47 & 4.69 & 1.484 & 8.33 & 21.00 & .11 & .10 \\
\hline Between whistles & 10 & 21.49 & 8.43 & 2.664 & 9.00 & 38.33 & .16 & .14 \\
\hline Time after the whistle & 10 & 4.92 & 3.93 & 1.242 & 2.17 & 12.33 & .04 & .03 \\
\hline Side change in 5 th set & 4 & 54.45 & 2.56 & 1.281 & 52.23 & 56.67 & .16 & .14 \\
\hline Other technical aspects & & & & & & & .03 & .02 \\
\hline Before the whistle & 1 & 8.50 & / & / & 8.50 & 8.50 & .01 & .01 \\
\hline Between whistles & 1 & 20.00 & / & 1 & 20.00 & 20.00 & .02 & .01 \\
\hline Time after the whistle & 1 & 2.50 & 1 & 1 & 2.50 & 2.50 & .00 & .00 \\
\hline Set duration & 123 & 1226.38 & 312.85 & 8.861 & 1132.76 & 1420.83 & 100 & / \\
\hline Match duration & 36 & 4190.08 & 1135.74 & 37.443 & 3398.27 & 6820.50 & / & 100 \\
\hline
\end{tabular}

Note. S = seconds. In the following tables all descriptive parameters (Mean, Std. Deviation, Std. Error, Min, and Max) are shown in seconds (s).

Mean set duration was $1226.38 \pm 312.85$ seconds (20.44 \pm 5.21 minutes), with the longest set lasting 1420.83 seconds (23.68 minutes) and the shortest lasting 1132.76 seconds (18.89 minutes). Mean match duration was $4190.08 \pm$ 1135.74 seconds $(69.83 \pm 18.93$ minutes $)$, with the longest and shortest matches lasting 6820.50 seconds (113.68 minutes) and 3398.27 seconds (56.64 minutes), respectively.

It is significant that the highest number of pauses between finished points and the referee's whistle for serve lasted more than 10 seconds in most cases (about 12 seconds) (Figure 3). The rules tested at the Championship attempted to control this aspect. Even though some pause periods lasted more than 20 seconds, the number of long pauses was kept to a reasonable level.

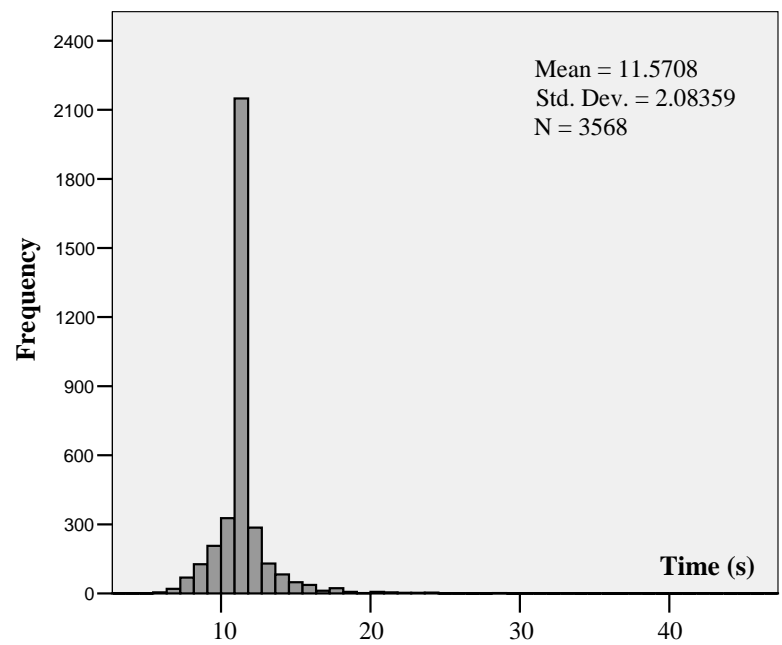

Figure 3. Distribution of pauses after rallies by duration. 


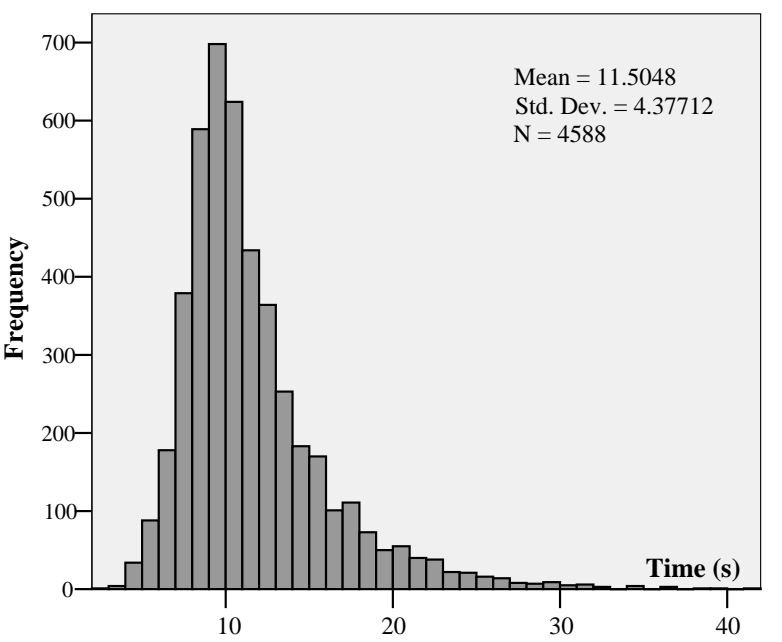

Figure 4. Distribution of finished points by duration.

The duration of the points finished during the matches analysed is worth noting. The most frequent point duration was 5 to 10 seconds (43.5\%) (Figure 4 ), followed by $41 \%$ of points lasting $10-15$ seconds. About $11 \%$ of the points finished during the match lasted 15-20 seconds and $3.7 \%$ lasted $20-25$ seconds.

Total team time-out lasted $13.03 \%$ of the match duration, more than twice the value for technical time-out $(6.09 \%$ of match duration).

Total team time-out, comprising time before the whistle for the beginning of time-out, time between whistles (time-out) and time after the whistle for the end of time-out until the next referee's signal (e.g., for serve or substitution), had a mean duration of 60.64 seconds. Total technical time-out had a mean duration of 77.11 seconds. Approximately 17 seconds lapsed from the end of team time-out until the new signal from the referee (e.g., for serve). The mean time spent during the period before the signal for the beginning of time-out was 8 seconds for team time-out and approximately 4 seconds for technical time-out.

For this study it was interesting to compare rally duration and rest time between rallies at different phases of the sets. The starting assumption was that the trend of the results would influence tactical acceleration or prolonging of the game. Variance analysis (Table 2) showed no significant difference between the mean duration of an active game in relation to Early, Middle and Final phase of the sets, although a significant difference was found between the mean duration of pauses or rest time after rallies and Early, Middle and Final phase of the sets (Table 3). Post hoc analysis showed that the source of variability was prolonging the pause in the Final phase of the sets. Rest time between points was almost the same in Early and Middle phase of the sets, with a value of 11.47 seconds.

Table 2

Rally duration in different phases of the set

\begin{tabular}{lcccccc}
\hline Phase of the set & $\mathrm{N}$ & Mean $(\mathrm{s})$ & Std. Dev. (s) & Std. Error (s) & Min. (s) & Max. (s) \\
\hline Early phase & 1723 & 11.69 & 4.55 & .109 & 3.67 & 38.00 \\
Middle phase & 1563 & 11.33 & 4.21 & .106 & 2.84 & 41.50 \\
Final phase & 1302 & 11.46 & 4.33 & .120 & 3.84 & 36.84 \\
Total & 4588 & 11.50 & 4.38 & .065 & 2.84 & 41.50 \\
\hline
\end{tabular}

$\mathrm{F}=2.855 ; p=.058$

Table 3

Duration of rest time after the rally in different phases of the set

\begin{tabular}{lcccccc}
\hline \multicolumn{1}{c}{ Phase of the set } & $\mathrm{N}$ & Mean $(\mathrm{s})$ & Std. Dev. (s) & Std. Error $(\mathrm{s})$ & Min. (s) & Max. (s) \\
\hline Early phase & 1721 & $\mathbf{1 1 . 4 6}$ & 1.28 & .03088 & 3.17 & 31.00 \\
\hline Middle phase & 1561 & $\mathbf{1 1 . 4 7}$ & 1.87 & .04745 & 5.17 & 41.84 \\
Final phase & 1299 & $\mathbf{1 1 . 8 1}$ & 2.34 & .06493 & 6.17 & 47.17 \\
Total & 4581 & $\mathbf{1 1 . 5 7}$ & 1.84 & .02717 & 3.17 & 47.17 \\
\hline
\end{tabular}

$\mathrm{F}=10.661^{*} ; p=.000$

One-way ANOVA was used to compare the mean point duration and mean pause duration in sets of different Win Level (Walkover, Balanced, and Tough set). Once again, a significant difference was found only for rest time after points (Tables 4 and 5). As sets became more unpredictable, rest time between points was longer. 
Table 4

Rally duration in sets of varying win level

\begin{tabular}{lcccccc}
\hline \multicolumn{1}{c}{ Phase of the set } & $\mathrm{N}$ & Mean (s) & Std. Dev. (s) & Std. Error (s) & Min. (s) & Max. (s) \\
\hline Walkover & 1889 & 11.48 & 4.22 & .097 & 3.84 & 36.84 \\
Balanced & 1414 & 11.43 & 4.43 & .118 & 2.84 & 41.50 \\
Tough & 1285 & 11.63 & 4.54 & .127 & 3.33 & 38.00 \\
Total & 4588 & 11.50 & 4.38 & .065 & 2.84 & 41.50 \\
\hline
\end{tabular}

$\mathrm{F}=.791 ; p=.453$

Table 5

Duration of rest time after the point in sets of varying win level

\begin{tabular}{lcccccc}
\multicolumn{1}{c}{ Phase of the set } & $\mathrm{N}$ & Mean (s) & Std. Dev. (s) & Std. Error (s) & Min. (s) & Max. (s) \\
\hline Walkover & 1882 & $\mathbf{1 1 . 3 1}$ & 1.41 & .033 & 3.67 & 30.17 \\
Balanced & 1414 & $\mathbf{1 1 . 4 3}$ & 1.87 & .050 & 3.17 & 41.84 \\
Tough & 1285 & $\mathbf{1 2 . 0 5}$ & 2.25 & .063 & 6.67 & 47.17 \\
Total & 4581 & $\mathbf{1 1 . 5 7}$ & 1.84 & .027 & 3.17 & 47.17 \\
\hline
\end{tabular}

$\mathrm{F}=43.585^{*} ; p=.000$

Total substitution time accounted for $6.05 \%$ of match duration and $6.88 \%$ of set time. The mean duration of substitutions was $10.27 \pm 4.72$ seconds and the maximum value for a single substitution was 60.17 seconds. The mean time for calling substitutions was $6.61 \pm 3.09$ seconds. Time between sets accounted for $12.04 \%$ of match duration and the mean value was $208.81 \pm$ 27.66 seconds (3.48 \pm 0.46 minutes). The longest period between sets was 399.33 seconds
(6.66 minutes) and the shortest period between sets was 143.84 seconds ( 2.40 minutes). A more in-depth analysis of time between sets revealed no significant differences (Table 6).

The shortest parts of sets and matches were sanctions, accounting for $0.31 \%$ of time in sets and $0.27 \%$ in matches, followed by the side change in the fifth set and other technical aspects (fixing a fallen antenna, fixing a problem with the referee's chair...). No time was spent on injuries.

Table 6

Duration of pauses after each set in numerical order

\begin{tabular}{lcccccc}
\multicolumn{1}{c}{ Time between sets } & $\mathrm{N}$ & Mean $(\mathrm{s})$ & Std. Dev. (s) & Std. Error (s) & Min. (s) & Max. (s) \\
\hline${\text { After } 1^{\text {st }} \text { set }}_{\text {After 2 }}^{\text {nd }}$ set & 36 & 204.83 & 16.42 & 2.737 & 153.67 & 235.67 \\
${\text { After } 3^{\text {rd }} \text { set }}_{\text {After 4 }}^{\text {th }}$ set & 36 & 210.77 & 38.02 & 6.337 & 143.84 & 399.33 \\
\hline Total & 11 & 207.12 & 14.36 & 4.328 & 171.50 & 225.17 \\
\hline
\end{tabular}

Kruskal-Wallis Chi Square $=6.933 ; p=.074$

\section{DISCUSSION}

Few studies have addressed time in volleyball and none have examined all time segments. In this study a work to rest ratio of approximately 1:1.86 was found for the match and 1:1.5 for the set. On comparing only points and pauses between points, the work to rest ratio is 1:1. Häyrinen et al. (2011) reported a work to rest ratio of 1:4.3 for men's elite matches and 1:3.5 for Under 19 (U19), but did not include timeouts or breaks between sets. According to Palao, Valadés, Manzanares, and Ortega (2014), the mean work to rest ratio in men's beach volleyball is $1: 4.42 \pm 5.73$. Kovacs (2004) reported a work to rest ratio in men's professional tennis of 1:2.67 within games and 1:4.73 within matches.

Häyrinen et al. (2011) found mean values for set duration of $26.3 \pm 2.2$ minutes for elite teams and $23.5 \pm 2.3$ minutes for U19 players, indicating a shorter set time by almost 6 minutes between $\mathrm{U} 23$ players and elite teams and about 3 minutes between U23 and U19 players. GarcíaAlcaraz, Palao, and Valadés (2012) reported a duration of 24 minutes for elite Spanish teams 
and 19.7 to 21.3 minutes for Under 14 (U14), Under 16 (U16) and U19 youth categories, although this study of U23 male players found that sets were 4 minutes shorter than in elite teams, with a small difference of 1 minute compared to U16 and U19. Only U14 had shorter sets, but the main reason could be the large difference in quality of play.

Compared to the results found by Häyrinen et al. (2011), a noticeable shortening of time breaks between rallies is observed, leading to more dynamic games and shorter matches. These authors reported a mean duration of the break between rallies of $23.54 \pm 5.55$ seconds for elite teams and $19.99 \pm 5.70$ seconds for U19 European top teams. Sheppard et al. (2007) found $44 \%$ of periods between rallies last 12 seconds or less, with a mean value of 14 seconds, compared to the value of $11.57 \pm 2.08$ seconds found in this study. The period between rallies in relation to Level of Set Win increased: between Walkover and Balanced sets it increased by 0.12 seconds and between Balanced and Tough sets the increase was 0.62 seconds.

The same tendency appeared in the different phases of the set. Between Early and Middle phases there was a small difference of 0.01 seconds, but between Middle and Final phases the increase was 0.34 seconds. The maximum rally duration in this study was 41.50 seconds, whereas in the study by Häyrinen et al. (2011) it was 39.9 seconds for the best 4 teams at the 2008 Olympic Games and 32.2 seconds for the best 4 teams at the U19 European Championship. Sheppard et al. (2007) found that $76.6 \%$ of rallies lasted 12 seconds or less, with an approximate mean rally of 11 seconds, although some lasted 3 seconds and others lasted up to 40 seconds. In this study the most frequent point duration was $5-10$ seconds $(43.5 \%)$, followed by points lasting $10-15$ seconds (41\%) and $15-20$ seconds (about $11 \%$ ), whereas only $3.7 \%$ lasted $20-25$ seconds. However, in the study by Häyrinen et al. (2011), rallies lasting less than 10 seconds were $84 \%$ for elite teams and $86 \%$ for U19 best teams, with $14 \%$ and 13\%, respectively, lasting 10-20 seconds, and $2 \%$ of rallies lasting more than 20 seconds for both men and youth players. Sánchez-Moreno, Marcelino, Mesquita, and
Ureña (2015) reported a mean length of $5.0 \pm$ 4.3 seconds for elite teams in world championships matches, compared to $11.50 \pm$ 4.38 seconds in this study. Point duration in the active part of the game was approximately the same as the mean time from the end of the point until the whistle for new serve. A comparison of the results with rally duration in other net and wall sports shows that volleyball is somewhere in the middle. In tennis the rally lasts 5-7 seconds (Kovacs, 2004; Smekal et al., 2001), in badminton 6.2 seconds (Férnandez-Férnandez, de la Aleja-Téllez, Moya-Ramón, CabelloManrique, \& Méndez-Villanueva, 2013), in beach volleyball 7.25 seconds (Palao et al., 2014) and in squash 18.6 seconds (Girard et al., 2007).

McCutcheon (2013) discussed eliminating technical time-outs in sets to 21 points, replacing them with two 1-minute team time-outs each team can use any time, and if neither team calls a time-out before the 11th point, TV time-out starts automatically. The results for team timeout duration show a large gap between the maximum value (64.33 seconds) and the minimum value (24.33 seconds), and between the maximum and minimum values of time after the whistle for the end of time-out (53 seconds and 1.84 seconds, respectively). The maximum value for before the whistle for time-out was 35.50 seconds and the minimum was 3.77 seconds. With the new rule tested, of 10 seconds until the server starts to serve, the coach has a limit of about 5 seconds to call the substitution, which appears to be a reasonable dynamic for the game and time fluctuation. Before the Brazil Championship there was debate about whether to incorporate free substitution to speed up and simplify the process and allow coaches more freedom for tactical subbing (McCutcheon, 2013). Häyrinen et al. (2011) reported values for time between sets of $217 \pm 17$ seconds ( $3.6 \pm$ 0.3 minutes) for elite players and $213 \pm 20$ seconds (3.6 \pm 0.3 minutes) for U19 players. Compared to the results found in this study, the difference is minimal and can be explained by referees strictly adhering to the rules. The shortest parts of sets and matches (sanctions, side change in $5^{\text {th }}$ set and other technical aspects) have little effect on duration. This study found 
only 4 matches that had $5^{\text {th }}$ set. The main characteristic of the $5^{\text {th }}$ set is side changing which belongs to resting time for all players. Average duration of the side change was 54.45 seconds, with minimum value of 52.23 seconds, and maximum value of 56.67 seconds. Only $0.16 \%$ of set time and $0.14 \%$ of match time was spent on side change, which belongs to negligible influential periods. However, every coach can count on those values as a chance to give several advises.

\section{CONCLUSION}

Game analysis shows there is scope for limiting pauses between rallies to 10 seconds, giving players adequate time to reach the serving position and 5 seconds to perform the serve. Onthe-fly substitutions of libero and middle blockers would need to be more synchronised.

Team and technical time-outs are two parts of rest time that can be adapted to make volleyball a more dynamic sport. The technology for technical time-outs should be applied to team time-outs to establish a clearer, automated time limit. The time after the whistle for the end of technical or team time-outs should be limited to 10-12 seconds so that after this time, all players must be ready on court with the server in position. The whole process will mean that calling for a team time-out will be indirectly limited to about 5 seconds, the time that coaches theoretically had at the U23 Championship in Brazil. These time limits will increase the dynamics of the game and decrease rest time.

The periods between rallies in the Early and Middle phases were almost identical, but shorter than in the Final periods. The difference was about 0.3 seconds, but it would be much longer without the experimental rule of 15 seconds between rallies. This shows that in the Final phase, when uncertainty is higher, most teams try to take advantage of longer pauses between rallies. This study can also have an influence on developing the structure of the volleyball game.

\footnotetext{
Acknowledgments:

The authors wish to thank Dr. Miljan Grbović, former physical trainer of the Serbian Volleyball National Team, for his wholehearted support and help in this
}

study, to Dr. José Afonso for his unreserved help regarding Portuguese, and the specially trained FIVB technicians, who are approved, supervised and appointed by the FIVB Technical Commission, for recording all the World Championship matches: Denis Popov (Russia), Manuel Abraham Calderón (Mexico), Saša Joksimović (Serbia) and Genaro López (Argentina). This study would not have been possible without the kind permission of the Fédération Internationale de Volleyball (FIVB) to use all the videos and information from the Under 23 Men's Volleyball World Championships.

Conflict of interests:

Nothing to declare.

\section{Funding:}

Nothing to declare.

\section{REFERÊNCIAS}

Claver, F., Jiménez, R., Gil, A., Moreno, A., \& Moreno, M. P. (2013). Relationship between performance in game actions and the match result. A study in volleyball training stages. Journal of Human Sport and Exercise, 8(Proc3), S651-S659. doi: 10.4100/jhse.2013.8.Proc3.11

Fellingham, G. W., Collings, B. J., \& McGown, C. M. (1994). Developing an optimal scoring system with a special emphasis on volleyball. Research Quarterly for Exercise and Sport, 65(3), 237-243. doi: 10.1080/02701367.1994.10607624

Fernández-Fernández, J., de la Aleja-Téllez, J. G., Moya-Ramón, M., Cabello-Manrique, D., \& Méndez-Villanueva, A. (2013). Gender differences in game responses during badminton match play. Journal of Strength and Conditioning Research, 29(9), 2396-2404. doi: 10.1519/JSC.0b013e31827fcc6a

FIVB (2012). Official volleyball rules 2013-2016. Retrieved

from http://www.fivb.org/en/Refereeing-

Rules/documents/FIVB-Volleyball_Rules2013EN_v2_20130422.pdf

FIVB (2013a). Twenty-one point rule to be tested at U23 World Championships. Retrieved from http://www.fivb.org/viewPressRelease.asp?No $=42863 \&$ Language $=$ en $\#$. VL5CBcaI9YE

FIVB (2013b). New rules test to be held in Brazil only. Retrieved from http://www.fivb.org/viewPressRelease.asp?No $=43147 \&$ Language $=$ en $\#$.VMOwz8aI9YE

FIVB (2013c). Competition formula. Retrieved from www.fivb.org/EN/volleyball/competitions/U23/ Men/2013/Formula.asp

FIVB (2015). Technical Survey (Summary of Men's U23 World Championship). Retrieved from

http://www.fivb.org/EN/TechnicalCoach/Document/FIVB_TE_U23_M_Summary. pdf 
García-Alcaraz, A., Palao, J. M., \& Valadés, D. (2012). Análisis de la duración de juego y la competitividad en diferentes categorías de competición en voleibol masculino [Analysis of the match duration and competitivity on different age groups in male volleyball]. Paper presented at the VII Congreso Internacional de la Asociación Española de Ciencias del Deporte, Granada, Spain.

Giatsis, G. (2003). The effect of changing the rules on score fluctuation and match duration in the FIVB women's beach volleyball. International Journal of Performance Analysis in Sport, 3(1), 57-64. doi: 10.14198/jhse.2015.102.01

Girard, O., Chevalier, R., Habrard, M., Sciberras, P., Hot, P., \& Millet, G. P. (2007). Game analysis and energy requirements of elite squash. Journal of Strength and Conditioning Research, 21 (3), 909914. doi:10.1519/R-20306.1

Häyrinen, M., Lehto, H., Mikkola, T., Honkanen, P., Lahtinen, P., Paananen, A., \& Blomqvist, M. (2011). Time analysis of men's and youth boy's top-level volleyball. British Journal of Sports Medicine, $\quad 45(6), \quad 542$. doi:10.1136/bjsm.2011.084558.25

Kountouris, P., \& Laios, Y. (2000). Changes affecting on the game of volleyball by the enforcement of the new regulations. Coaching Volleyball, 17(1), 26-30.

Kovacs, M. (2004). A comparison of work/rest intervals in men's professional tennis. Medicine and Science in Tennis, 9(3), 10-11.

Landis, J. R., \& Koch, G. G. (1977). The measurement of observer agreement for categorical data. Biometrics, 33(1), 159-174. doi:10.2307/2529310

Marcelino, R., \& Mesquita, I. (2008, January). Associations between performance indicators and set's result on male volleyball. Paper presented at the meeting of the $5^{\text {th }}$ International Scientific Conference on Kinesiology, Zagreb, Croatia.

Marcelino, R., Mesquita, I., \& Afonso, J. (2008). The weight of terminal actions in volleyball. Contributions of the spike, serve and block for the teams' rankings in the World League 2005. International Journal of Performance Analysis in Sport, 8(2), 1-7. doi: 10.1515/1559-0410.1348

Marcelino, R., Mesquita, I., Palao, J. M., \& Sampaio, J. (2009). Home advantage in high-level volleyball varies according to set number. Journal of Sports Science and Medicine, 8(3), 352-356.
McCutcheon, H. (2013). Re: Game changer [Web log message]. Retrieved from http://www.teamusa.org/usavolleyball/features/2014/september/16/gamechangers

Palao, J. M., Valadés, D., Manzanares, P., \& Ortega, E. (2014). Physical actions and work-rest time in men's beach volleyball. Motriz: Revista de Educação Física, 20(3), 257-261. doi:10.1590/S198065742014000300003

Palao, J. M., Valadés, D., \& Ortega, E. (2012). Match duration and number of rallies in men's and women's 2000-2010 FIVB world tour beach volleyball. Journal of Human Kinetics, 34(1). 99104. doi:10.2478/v10078-012-0068-7

Sánchez-Moreno, J., Marcelino, R., Mesquita, I., \& Ureña, A. (2015). Analysis of the rally length as a critical incident of the game in elite male volleyball. International Journal of Performance Analysis in Sport, 15(2), 620-631.

Sheppard, J. M., Gabbett, T., Taylor, K. L., Dorman, J., Lebedew, A. J., \& Borgeaud, R. (2007). Development of a repeated-effort test for elite men's volleyball. International Journal of Sports Physiology and Performance, 2(3), 292-304.

Smekal, G., Von Duvillard, S. P., Rihacek, C., Pokan, R., Hofmann, P., Baron, R., ... Bachl, N. (2001). A physiological profile of tennis match play. Medicine and Science in Sports and Exercise, 33 (6), 999-1005. doi:10.1097/00005768-20010600000020

Tsimpiris, A., Tsamourtzis, E., Sfingos, N., Zaggelidis, G., \& Zaggelidis, S. (2006). A multimedia application for tactic analysis of basketball games. Revista Stiinta Sportului, 15, 17-39.

Ureña, A., Gallardo, C., Delgado, J., Hernández, E., \& Calvo, R. (2000). Estudio sobre la evolución de las reglas de juego en voleibol [Study of the history of volleyball rules of the game]. Habilidad Motriz: Revista de Ciencias de la Actividad Física y del Deporte, 16, 32-39.

Vilamitjana, J. J., Soler, D., Barrial, J. M., Del Grecco, P., Montes de Oca, M., \& Rodríguez, F. (2008). Jumping profile of elite volleyball male players by field positions during a competitive season. Medicine E Science in Sports \& Exercise, 40(5), S383. doi:10.1249/01.mss.0000322635.00958.95 